\title{
Surgical Outcomes of a Combined Surgical Approach for Apical Prolapse Repair
}

\section{Resultados cirúrgicos de uma abordagem cirúrgica combinada para a correção do prolapso apical}

\author{
Luiz Gustavo Oliveira Brito ${ }^{1}$ Sarah Lauren Cohen ${ }^{1}$ \\ Emily Rose Goggins ${ }^{1}$ Jon Ivar Einarsson ${ }^{1}$ \\ ${ }^{1}$ Minimally Invasive Gynecological Surgery Division, Department of
Obstetrics, Gynecology and Reproductive Biology, Brigham and Women's \\ Hospital, Harvard Medical School, Boston, Massachusetts, United States \\ 2 Boston Urogyn, Wellesley, Massachusetts, United States
}

Olga Tusheva ${ }^{1}$ Neeraj Kohli ${ }^{2}$ Abraham Morse ${ }^{2}$

\begin{abstract}
Address for correspondence Jon Ivar Einarsson, MD, MPH, PhD, Brigham and Women's Hospital, Minimally Invasive Gynecological Surgery Division, 75 Francis Street, ASB 1-3 - Boston, MA 02115, United States (e-mail: jeinarsson@partners.org).
\end{abstract}

\begin{abstract}
Keywords

- sacrocolpopexy

- operative time

- combined surgery

- apical prolapse
\end{abstract}

Introduction We aimed to evaluate the safety, efficacy and surgical outcomes of combined laparoscopic/vaginal prolapse repair by two surgeons.

Material and Methods A retrospective chart review of all patients $(n=135)$ who underwent apical prolapse repair from February 2009 to December 2012 performed in a collaborative manner by a Minimally Invasive Gynecologic Surgeon and a Urogynecologist. Demographic data (age, body mass index [BMI], race, gravidity, parity) and surgical information (estimated blood loss, operative time, intraoperative complications, readmission and reoperation rates, presence of postoperative infection) were collected.

Results The majority of patients were postmenopausal (58.91\%), multiparous (mean parity $=2.49$ ) and overweight (mean $\mathrm{BMI}=27.71$ ). Nearly $20 \%$ had previous prolapse surgery. The most common surgical procedure was laparoscopic supracervical hysterectomy (LSH) with sacrocervicopexy (59.26\%), and the most common vaginal repair was of the posterior compartment (78.68\%). The median operative time was 149 minutes (82-302), and the estimated blood loss was $100 \mathrm{~mL}(10-530)$. Five intraoperative complications, five readmissions and four reoperations were noted. Performance of a concomitant hysterectomy did not affect surgical or anatomical outcomes. Conclusion Combination laparoscopic/vaginal prolapse repair by two separate surgeons seems to be an efficient option for operative management.

\section{Resumo}

Introdução Objetivamos avaliar a segurança, eficácia e desfechos cirúrgicos da via laparoscópica e vaginal combinadas para a correção do prolapso feitos por dois cirurgiões.

Métodos Um estudo retrospectivo com análise de prontuário foi realizado em todos os pacientes $(n=135)$ que foram submetidos a correção de prolapso apical de fevereiro de 2009 a dezembro de 2012 de maneira concomitante por um received April 7, 2016 accepted July 1, 2016 published online August 16, 2016
DOI http://dx.doi.org/ 10.1055/s-0036-1586747. ISSN 0100-7203.
Copyright $\odot 2016$ by Thieme Publicações License terms Ltda, Rio de Janeiro, Brazil 


\author{
Palavras-chave \\ - sacrocolpopexia \\ - tempo operatório \\ - cirurgia combinada \\ - prolapso apical
}

laparoscopista e um uroginecologista. Dados demográficos (idade, índice de massa corporal [IMC], raça, número de gestações e partos) e cirúrgicos (perda sanguínea estimada, tempo operatório, complicações intraoperatórias, taxas de readmissão e reoperação, e presença de infecção pós-operatória) foram analisados.

Resultados O perfil da paciente operada era pertencente à pós-menopausa $(58,91 \%)$, ser multípara (paridade média $=2,49$ ) e com sobrepeso $($ IMC médio $=27,71$ ). Aproximadamente $20 \%$ havia feito cirurgia prévia para prolapso. O procedimento cirúrgico mais realizado foi a histerectomia supracervical laparoscópica (HSL) com sacrocervicopexia (59,6\%); o reparo vaginal mais encontrado foi o para defeito de compartimento posterior (78,68\%). O tempo operatório mediano foi de 149 minutos (82-302), e a perda sanguínea estimada foi de $100 \mathrm{ml}$ (10-530). Cinco complicações pós-operatórias, cinco readmissões e quatro reoperações foram encontradas. A realização de uma histerectomia em concomitância aos demais procedimentos não afetou os desfechos cirúrgicos ou anatômicos.

Conclusão O reparo combinado do prolapso pela via laparoscópica e vaginal por dois cirurgiões em concomitância aparenta ser uma opção eficiente para o manejo operatório.

\section{Introduction}

Pelvic organ prolapse (POP) is a common condition worldwide, ${ }^{1}$ and the demand for reconstructive surgery is expected to increase by $45 \%$ over the next three decades due to aging. ${ }^{2}$ Despite the evolution of surgical management options, $\mathrm{POP}$ continues to be associated with recurrence rates as high as $50-60 \%{ }^{3}$

Three main components to POP are recognized: anterior, posterior and apical support defects. Most POP defects are combined, and the lack of recognition of multi-compartment defects may increase the risk of post-operative recurrence. Posterior and anterior defects are most commonly treated via vaginal approach, while abdominal sacrocolpopexy with mesh is currently considered the first option treatment for apical prolapse. ${ }^{3}$ Recent advances in minimally invasive surgery have led to the development of a laparoscopic approach to apical prolapse repair, which combines the effectiveness of sacrocolpopexy with the reduced morbidity traditionally associated with the vaginal approach. ${ }^{4}$

To our knowledge, the role of a combined surgical approach to POP treatment has not been established yet. The rationale behind the development of a joint approach is based on the optimization of operating time and surgeon experience with different surgical approaches (vaginal and laparoscopic) to enhance patient outcomes. In the present study, we sought to retrospectively evaluate perioperative outcomes associated with a combined approach to pelvic prolapse repair.

\section{Methods}

\section{Study Design}

This retrospective chart review was approved by The Partners Institutional Review Board. The study included 135 patients who underwent a combined approach for apical and mid-compartment prolapse repair between
February 2009 and December 2012 at Brigham and Women's Hospital. Surgical databases from the Division of Minimally Invasive Gynecological Surgery and the Division of Urogynecology were reviewed. Patients who underwent apical prolapse repair with or without other types of prolapse repair and concomitant procedures were included in the study. Patients who presented with gynecological malignancies or current genital infections were excluded. The following variables were extracted from the medical record: age, ethnicity, body mass index (BMI), parity, previous history of prolapse surgery, type of prolapse defect, procedures performed at the index surgery, previous history of hysterectomy, and the presence of the cervix. Surgical outcomes included: estimated blood loss, operative time (time from incision to complete wound closing), intraoperative bladder or bowel injury, readmission and reoperation rates, and presence of postoperative infection.

The Pelvic Organ Prolapse Quantification (POP-Q) classification was obtained at baseline and three weeks postoperatively. The follow-up period varied from 1 to 12 months. Additionally, the presence of complications, including infection, mesh erosion or irritation, was recorded. Prolapse recurrence after a six-month follow-up period was also assessed.

\section{Statistical Analysis}

Binomial variables were analyzed by the chi-square test, and continuous variables were analyzed by a two-sided $t$-test. A significance level of $5 \%$ was established. Statistical analyses were performed using the Intercooled Stata version 12.0 (Stata Statistical Software: Release 13. College Station, TX: StataCorp LP, USA) software.

\section{Surgical Technique}

The combined approach for apical prolapse repair included participation of two high volume surgeons experienced in prolapse repair; one minimally invasive gynecologic surgeon 
(JIE) and one of two urogynecologists (NK, ANM). The minimally invasive surgeon commonly performed a laparoscopic hysterectomy, if indicated, and a laparoscopic repair of the apical prolapse; the urogynecologist was responsible for the vaginal repairs. No mesh was utilized in the vaginal compartment, except when the procedure included a mid-urethral sling for documented preoperative stress incontinence.

The technique for laparoscopic sacrocolpopexy or sacrocervicopexy is as previously reported. ${ }^{5,6}$ Briefly, the bladder was dissected off the anterior surface of the cervix and upper vagina (or simply the vagina, if they were without cervix), and the rectovaginal septum was developed, separating the rectum from the vagina posteriorly using the Harmonic scalpel (Ethicon Endo-Surgery, Cincinnati, OH, USA) and blunt dissection. A Yshaped polypropylene mesh (Prolene ${ }^{\circledR}$, Ethicon Surgery, Cincinnati, OH, USA) was attached to the anterior and posterior aspects of the cervical stump and the upper vagina with interrupted Ethibond ${ }^{\circledR}$ (Ethicon Surgery, Cincinnati, OH, USA) sutures that were tied intracorporeally. Typically, six fixation points were placed anteriorly and six posteriorly. The sacral fixation was either performed using a Protack device (Covidien, New Haven, CT, USA) or with suture. The mesh was always completely retroperitonealized at the end of the procedure. The urogynecologist subsequently performed a traditional anterior and/or posterior repair and/or perineorrhaphy and mid-urethral (retropubic or transobturator) sling procedure, if indicated, following hysterectomy and/or attachment of the mesh to the apex, but prior to the final tie-down of the sacral suspension sutures. Cystoscopy was performed on all patients with the administration of either indigo carmine, methylene blue or preoperative phenazopyridine.

\section{Results}

Demographic data are displayed in $\boldsymbol{-}$ Table $\mathbf{1}$. The majority of patients were white, postmenopausal, overweight and multiparous. Almost all patients (98.51\%) had apical prolapse, as well as posterior (59.3\%) and anterior (56.3\%) defects. The most commonly performed apical prolapse procedure was sacrocervicopexy ( $n=87)$, followed by uterosacral ligament suspension $(n=15)$, sacrocolpopexy $(n=7)$, hysteropexy $(n=4)$, and laparoscopic paravaginal repair $(n=2)$. With regard to the vaginal repair, posterior colporrhaphy was the most common repair (78.68\%), followed by anterior (72.06\%) and perineorrhaphy (58.09\%).

With regard to surgical outcomes, the median operating time was 149 minutes (range 82-302), and the median estimated blood loss was $100 \mathrm{~mL}$ (10-530). Five patients (4\%) experienced an intraoperative bladder injury, three during the laparoscopic portion of the procedure, and two during vaginal surgery, all of which were noted and repaired intraoperatively by the primary surgical team. No bowel injuries were found. There were no other intraoperative complications. There were no conversions to a laparotomy. Postoperative complications included 3 mesh-related infections (2.5\%), with $2(1.5 \%)$ cases requiring reoperation for mesh removal due to pelvic abscesses. Eight patients (6.6\%) experienced prolapse recurrence with a median follow-up time of 8 months respectively.
Table 1 Demographic and perioperative variables from studied patients

\begin{tabular}{|c|c|c|}
\hline Variable & $\begin{array}{l}\text { Median } \\
\text { (range) }\end{array}$ & N (\%) \\
\hline Age (years) & $55(31-78)$ & \\
\hline BMI $\left(\mathrm{kg} / \mathrm{m}^{2}\right)$ & $\begin{array}{l}26.60 \\
(18.52-51.30)\end{array}$ & \\
\hline Gravidity & $3(0-12)$ & \\
\hline Parity & $2(0-9)$ & \\
\hline \multicolumn{3}{|l|}{ Menopausal status } \\
\hline Premenopause & & $53(41.1 \%)$ \\
\hline Postmenopause & & $76(58.9 \%)$ \\
\hline \multicolumn{3}{|l|}{ Prior prolapse surgery } \\
\hline Yes & & $22(16.3 \%)$ \\
\hline No & & $\begin{array}{l}113 \\
(83.7 \%)\end{array}$ \\
\hline \multicolumn{3}{|c|}{ Type of surgery for apical prolapse* } \\
\hline LSH + sacrocervicopexy & & $\begin{array}{l}80 \\
(59.3 \%)\end{array}$ \\
\hline Sacrocolpopexy & & $22(62.9 \%)$ \\
\hline TLH + USLS & & $11(8.1 \%)$ \\
\hline Sacrocervicopexy & & $7(5.2 \%)$ \\
\hline TLH + sacrocolpopexy & & $5(3.7 \%)$ \\
\hline Histeropexy & & $4(2.9 \%)$ \\
\hline LSH + USLS & & $3(2.2 \%)$ \\
\hline LSC paravaginal repair & & $2(1.5 \%)$ \\
\hline USLS & & $1(0.7 \%)$ \\
\hline \multicolumn{3}{|c|}{ Concomitant type of vaginal repair } \\
\hline Anterior colporrhaphy & & $98(72.6 \%)$ \\
\hline Posterior colporrhaphy & & $\begin{array}{l}107 \\
(79.5 \%)\end{array}$ \\
\hline Perineorrhaphy & & $79(58.5 \%)$ \\
\hline Operative time (minutes) & $\begin{array}{l}149 \\
(82-302)\end{array}$ & \\
\hline $\mathrm{EBL}(\mathrm{mL})$ & $\begin{array}{l}100 \\
(10-330)\end{array}$ & \\
\hline Length of stay (days) & $1(0-3)$ & \\
\hline Intraoperative complications & & $5(3.7 \%)$ \\
\hline
\end{tabular}

Abbreviations: BMI, body mass index; EBL, estimated blood loss; LSC, laparoscopic; LSH, laparoscopic supracervical hysterectomy; TLH, total laparoscopic hysterectomy; USLS, uterosacral ligament suspension. *More than one surgery on the same patient.

- Table 2 separates the study population based on history of previous hysterectomy, and - Table 3 displays the results with regard to the presence or absence of the cervix. Patient populations in all compared groups were homogeneous with regard to age, ethnicity, BMI, parity, history of previous prolapse surgery, type of prolapse and concomitant procedures, excluding lysis of adhesions. The mean change in POP$\mathrm{Q}$ measurements did not differ significantly between the 
Table 2 Comparison of outcomes in patients with previous hysterectomy versus concomitant hysterectomy during apical repair

\begin{tabular}{|c|c|c|c|}
\hline Variable & $\begin{array}{l}\text { Prior hysterectomy } \\
(n=36)\end{array}$ & $\begin{array}{l}\text { Concomitant hysterectomy } \\
(n=99)\end{array}$ & $p$ \\
\hline Age (mean/SD - years) & $57.5 \pm 7.5$ & $54.8 \pm 9$ & $0.18^{\mathrm{a}}$ \\
\hline BMI (mean/SD - kg/m²) & $26.3 \pm 3.9$ & $28.4 \pm 6.9$ & $0.36^{\mathrm{a}}$ \\
\hline Gravidity (mean/SD) & $2.80 \pm 1.64$ & $3.35 \pm 1.88$ & $0.12^{\mathrm{a}}$ \\
\hline Parity (mean/SD) & $2.33 \pm 1.07$ & $2.54 \pm 1.32$ & $0.39^{\mathrm{a}}$ \\
\hline \multicolumn{3}{|l|}{ Race (n/\%) } & $0.25^{\mathrm{b}}$ \\
\hline White & $31(86.1 \%)$ & 87 (87.9\%) & \\
\hline African American & $2(5.6 \%)$ & $2(2 \%)$ & \\
\hline Hispanic/other & $3(8.3 \%)$ & $8(10.1)$ & \\
\hline Prior prolapse surgery (n/\%) & $13(36.1 \%)$ & $9(2.8 \%)$ & $0.01^{\mathrm{b}}$ \\
\hline \multicolumn{4}{|l|}{ Prolapse subtype (n/\%) } \\
\hline Anterior & $21(58.3 \%)$ & $56(56.6 \%)$ & $0.85^{\mathrm{b}}$ \\
\hline Posterior & $20(55.5 \%)$ & $60(60.6 \%)$ & $0.60^{\mathrm{b}}$ \\
\hline Uterine & & $98(98.9 \%)$ & $0.45^{\mathrm{b}}$ \\
\hline Vaginal vault & $13(36.1 \%)$ & $4(0.4 \%)$ & $0.01^{\mathrm{b}}$ \\
\hline \multicolumn{4}{|l|}{ Concomitant procedures (n/\%) } \\
\hline Transobturator sling & $8(22.2 \%)$ & $17(17.2 \%)$ & $0.02^{\mathrm{b}}$ \\
\hline Retropubic sling & $4(11.1 \%)$ & 35 (35.4\%) & $0.02^{\mathrm{b}}$ \\
\hline Cystoscopy & $31(86.1 \%)$ & $84(84.8 \%)$ & $0.85^{\mathrm{b}}$ \\
\hline LSC adhesiolysis & $17(47.2 \%)$ & $16(16.2 \%)$ & $0.01^{\mathrm{b}}$ \\
\hline Anexectomy & $3(8.3 \%)$ & $20(20.2 \%)$ & $0.10^{\mathrm{b}}$ \\
\hline $\begin{array}{l}\text { Surgical variables }(\mathrm{n} / \%) \\
\text { EBL (mean/SD - mL) }\end{array}$ & $95.14 \pm 88.09$ & $89.85 \pm 51.30$ & $0.67^{\mathrm{a}}$ \\
\hline Operative time (mean/SD - minutes) & $117.67 \pm 36.83$ & $132.19 \pm 38.47$ & $0.05^{\mathrm{a}}$ \\
\hline Readmission & $1(2.8 \%)$ & $3(3 \%)$ & $0.92^{\mathrm{b}}$ \\
\hline Reoperation & $2(5.6 \%)$ & $3(3 \%)$ & $0.52^{\mathrm{b}}$ \\
\hline Postoperative infection & $4(11.1 \%)$ & $8(8 \%)$ & $0.65^{\mathrm{b}}$ \\
\hline Prolapse recurrence (6 months $\mathrm{F} / \mathrm{U}$ ) & $4(11.1 \%)$ & $3(3 \%)$ & $0.09^{\mathrm{b}}$ \\
\hline \multicolumn{3}{|l|}{ Mesh complications (n/\%) } & $0.09^{\mathrm{b}}$ \\
\hline Infection & $2(5.5 \%)$ & 0 & \\
\hline Infection and erosion & 0 & $1(0.9 \%)$ & \\
\hline Other complications & 0 & $3(3 \%)$ & \\
\hline \multicolumn{4}{|l|}{ Mean change in POP-Q measurements } \\
\hline $\mathrm{Aa}$ & -3.46 & -2.96 & $0.26^{\mathrm{a}}$ \\
\hline $\mathrm{Ba}$ & -5.29 & -3.59 & $0.69^{\mathrm{a}}$ \\
\hline $\mathrm{C}$ & -8.68 & -6.53 & $0.38^{\mathrm{a}}$ \\
\hline $\mathrm{D}$ & -5 & -5.04 & $0.81^{\mathrm{a}}$ \\
\hline Ap & -2.11 & -1.21 & $0.09^{\mathrm{a}}$ \\
\hline $\mathrm{Bp}$ & -2.96 & -1.33 & $0.07^{\mathrm{a}}$ \\
\hline Gh & -2.32 & -2 & $0.29^{\mathrm{a}}$ \\
\hline $\mathrm{Pb}$ & 0.14 & 0.01 & $0.70^{\mathrm{a}}$ \\
\hline TVL & 0.18 & 0.32 & $0.44^{\mathrm{a}}$ \\
\hline
\end{tabular}

Abbreviations: EBL, estimated blood loss; F/U, follow-up; POP-Q, Pelvic Organ Prolapse Quantification; SD, standard deviation. ${ }^{a}$ Determined by $t$-test (two-sided).

betermined by chi-square test. 
Table 3 Comparison of outcomes in patients with no cervix versus cervix present during apical repair

\begin{tabular}{|c|c|c|c|}
\hline Variable & $\begin{array}{l}\text { Cervix absent } \\
(n=89)\end{array}$ & $\begin{array}{l}\text { Cervix present } \\
(n=46)\end{array}$ & $p$ \\
\hline Age (mean/SD - years) & $54.94 \pm 9.81$ & $54.28 \pm 10.18$ & $0.71^{\mathrm{a}}$ \\
\hline BMI $\left(\right.$ mean $\left./ S D-k g / m^{2}\right)$ & $26.9 \pm 3.7$ & $28.1 \pm 6.9$ & $0.95^{a}$ \\
\hline Gravidity (mean/SD) & $3.29 \pm 1.74$ & $3.02 \pm 1.98$ & $0.41^{\mathrm{a}}$ \\
\hline Parity (mean/SD) & $2.48 \pm 1.13$ & $2.47 \pm 1.47$ & $0.96^{a}$ \\
\hline \multicolumn{3}{|l|}{ Race (n/\%) } & $0.55^{b}$ \\
\hline White & 77 (86.5\%) & $41(89.1 \%)$ & \\
\hline African American & $2(2.2 \%)$ & $2(4.3 \%)$ & \\
\hline Hispanic/other & 7 (7.9\%) & $1(2.2 \%)$ & \\
\hline Prior prolapse surgery (n/\%) & $7(7.9 \%)$ & $15(32.6 \%)$ & $0.00^{\mathrm{b}}$ \\
\hline \multicolumn{4}{|l|}{ Prolapse subtype (n/\%) } \\
\hline Anterior & $51(57.3 \%)$ & $26(56.5 \%)$ & $0.93^{b}$ \\
\hline Posterior & $55(61.8 \%)$ & $25(54.3 \%)$ & $0.40^{\mathrm{b}}$ \\
\hline Uterine & & $44(95.6 \%)$ & $0.05^{b}$ \\
\hline Vaginal vault & $89(100 \%)$ & $13(28.3 \%)$ & $0.00^{\mathrm{b}}$ \\
\hline \multicolumn{4}{|l|}{ Concomitant procedures (n/\%) } \\
\hline Transobturator sling & $15(16.9 \%)$ & $10(17.9 \%)$ & $0.23^{b}$ \\
\hline Retropubic sling & $30(30.3 \%)$ & $9(19.6 \%)$ & $0.23^{b}$ \\
\hline Cystoscopy & $74(83.2 \%)$ & $41(89.1 \%)$ & $0.35^{b}$ \\
\hline LSC adhesiolysis & $15(16.9 \%)$ & $18(39.1 \%)$ & $0.00^{\mathrm{b}}$ \\
\hline Anexectomy & 15 (16.9\%) & $8(17.4 \%)$ & $0.94^{b}$ \\
\hline \multicolumn{4}{|l|}{ Surgical variables (n/\%) } \\
\hline $\begin{array}{l}\text { EBL (mean/SD - mL) } \\
\text { Operative time (mean/SD - minutes) }\end{array}$ & $\begin{array}{l}95 \pm 49.93 \\
131.87 \pm 39.13 \\
\end{array}$ & $\begin{array}{l}84.02 \pm 82.61 \\
121.46 \pm 36.53 \\
\end{array}$ & $\begin{array}{l}0.33^{\mathrm{a}} \\
0.13^{\mathrm{a}} \\
\end{array}$ \\
\hline Readmission & $3(3.3 \%)$ & $1(2.2 \%)$ & $0.64^{b}$ \\
\hline Reoperation & $3(3.3 \%)$ & $2(4.3 \%)$ & $0.77^{b}$ \\
\hline Postoperative infection & $8(8.9 \%)$ & $4(8.7 \%)$ & $0.97^{b}$ \\
\hline Prolapse recurrence (6 months $\mathrm{F} / \mathrm{U}$ ) & $5(5.6 \%)$ & $2(4.3 \%)$ & $0.74^{b}$ \\
\hline \multicolumn{3}{|l|}{ Mesh complications (n/\%) } & $0.09^{b}$ \\
\hline Infection & $2(2.2 \%)$ & 0 & \\
\hline Infection and erosion & 0 & $1(2.2 \%)$ & \\
\hline Other complications & 0 & $3(6.5 \%)$ & \\
\hline \multicolumn{4}{|l|}{ Mean change in POP-Q measurements } \\
\hline $\mathrm{Aa}$ & -3.88 & -2.83 & $0.03^{a}$ \\
\hline $\mathrm{Ba}$ & -5.81 & -3.46 & $0.01^{\mathrm{a}}$ \\
\hline C & -10.31 & -6.04 & $0.01^{a}$ \\
\hline $\mathrm{D}$ & -12.00 & -4.46 & $0.02^{a}$ \\
\hline Ap & -1.96 & -1.29 & $0.51^{a}$ \\
\hline Bp & -3.31 & -1.26 & $0.12^{\mathrm{a}}$ \\
\hline Gh & -2.54 & -1.94 & $0.06^{a}$ \\
\hline $\mathrm{Pb}$ & 0.04 & 0.05 & $0.88^{a}$ \\
\hline TVL & 0.27 & 0.28 & $0.75^{\mathrm{a}}$ \\
\hline
\end{tabular}

Abbreviations: BMI, body mass index; EBL, estimated blood loss; F/U, follow-up; LSC, laparoscopic; POP-Q, pelvic organ prolapse quantification; SD, standard deviation.

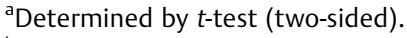

${ }^{b}$ Determined by chi-square test. 
concomitant hysterectomy and the prior hysterectomy groups ( - Table 2). However, it differed significantly between mesh procedures with cervix present versus prior cervix removal for the following POP-Q points: Aa $(p=0.03)$, Ba $(p=0.01), \mathrm{C}(p=0.01)$ and $\mathrm{D}(p=0.02)$; this means that the apical and anterior compartments had a higher length when removing the cervix ( - Table $\mathbf{3}$ ).

\section{Discussion}

This study indicates that the combined approach for apical prolapse is associated with a relatively short operating time, minimal blood loss, and a low number of complications. Research on combined surgeries from other specialties indicates that a combined approach enhanced their surgical outcomes. $^{7,8}$ However, similar reports are absent from the gynecologic literature. We believe this report is the first to document a substantial case series with a laparoscopic/ vaginal approach utilizing two separate surgeons. A report of a vaginally assisted laparoscopic sacrocolpopexy was recently published, but it doesn't refer if it combines surgeons from different specialties. ${ }^{9}$

In our data, we observed a median total operating time of 149 minutes, including the vaginal portion of the case. When compared with previous studies of laparoscopic sacrocolpopexy without a combined approach, they have shown a mean operating time varying from $180-236$ minutes. ${ }^{10-13}$ Our relatively short operative time may reflect the high volume and experience of the surgeons in this study, and could also be related with the ability of the urogynecologist to start the vaginal portion before the laparoscopic portion is finished.

As expected when compared with previous studies, ${ }^{11,12}$ more than half $(59.2 \%)$ of patients with apical prolapse presented with other defects. It is unclear if a combined approach would foster an improvement in postoperative outcomes while potentially reducing the rate of prolapse recurrence and the associated long-term costs. Our followup period was short, and therefore it is not possible to assess this variable with certainty. Future prospective cohort studies could seek to evaluate if there are any differences in postoperative outcomes and prolapse recurrence with regard to procedures done by joint teams.

Another goal of this study was to investigate the effect of concomitant versus prior hysterectomy and the presence or absence of the cervix at the time of the surgery on postoperative outcomes according to the POP-Q system. Concerns regarding concomitant hysterectomy at the time of sacrocolpopexy have been raised in the literature. ${ }^{3,14,15}$ While no randomized trials explored this issue, several small studies reported an increased risk for erosion in the setting of concomitant hysterectomy, ${ }^{14,15}$ while others did not. ${ }^{16,17}$ In the current study, hysterectomy at the time of sacrocolpopexy with mesh placement was not associated with a significantly increased risk of mesh related infection or erosion (-Table 2). However, the majority of our hysterectomies were supracervical due to support in the literature for decreased risk of mesh erosion in this class of hysterectomy. ${ }^{18}$
There was a higher recurrence of prolapse in the group without a cervix at 6 months follow-up (11.1 versus 3\%), although this was not statistically significant. This may have clinical importance in regards to counseling patients about the risk of recurrence. Other surgical and anatomic variables did not differ between groups with prior or concomitant hysterectomy. Interestingly, patients without a cervix in place were found to have significantly better postoperative outcomes at $\mathrm{Aa}, \mathrm{Ba}, \mathrm{C}$ and $\mathrm{D}$ points ( - Table $\mathbf{3}$ ). Our study does have some limitations. Firstly, it is retrospective, and lacks a control group to make quantitative comparisons between outcome measures. Results are interesting, but we will certainly need studies with higher sampling with a comparative group. Secondly, some institutions may not have subspecialists in minimally invasive gynecology and urogynecology, and these results may not be useful in these scenarios. Thirdly, relapses from POP patients could not be ideally detected due to the short-term follow-up; a longer period to see the effects of surgery over the pelvic floor is necessary.

Overall, our study demonstrated that a combined approach for apical prolapse repair seems to be safe and feasible. Due to the lack of consensus about the preferred management of POP defects, our combined surgical strategy offers an attractive alternative to the currently existing approaches, and a useful addition to the armamentarium of urogynecologists and minimally invasive surgeons. This experience has been favorable in our setting; we are piloting an outpatient program for this combined approach, and we hope to confirm these results. Future studies are needed to explore if this initiative can help enhance patient outcomes.

\section{Key Message}

The combination of two separate surgeons for apical prolapse repair seems to be an efficient choice for operative management.

\section{Acknowledgments}

We would like to thank São Paulo Research Foundation (Fapesp), grant n. 13/25956-0, which sponsored Dr. Brito's post-doctoral research fellowship.

\section{References}

1 Olsen AL, Smith VJ, Bergstrom JO, Colling JC, Clark AL. Epidemiology of surgically managed pelvic organ prolapse and urinary incontinence. Obstet Gynecol 1997;89(4):501-506

2 Luber KM, Boero S, Choe JY. The demographics of pelvic floor disorders: current observations and future projections. Am J Obstet Gynecol 2001;184(7):1496-1501, discussion 1501-1503

3 Gilleran JP, Johnson M, Hundley A. Robotic-assisted laparoscopic mesh sacrocolpopexy. Ther Adv Urol 2010;2(5-06):195-208

4 Cvach K, Dwyer P. Surgical management of pelvic organ prolapse: abdominal and vaginal approaches. World J Urol 2012;30(4): 471-477

5 Nezhat CH, Nezhat F, Nezhat C. Laparoscopic sacral colpopexy for vaginal vault prolapse. Obstet Gynecol 1994;84(5):885-888 
6 Wieslander CK, Rahn DD, McIntire DD, et al. Vascular anatomy of the presacral space in unembalmed female cadavers. Am J Obstet Gynecol 2006;195(6):1736-1741

7 Palou J, Oliveira M, Pardo P, et al. [Combined approach of laparoscopic and open surgery for complex renal lesions]. Actas Urol Esp 2013;37(2):120-126 Spanish.

8 Kong DS, Kwon KH, Kim JS, Hong SC, Jeon P. Combined surgical approach with intraoperative endovascular embolization for inaccessible dural arteriovenous fistulas. Surg Neurol 2007; 68(1):72-77, discussion 78

9 Athanasiou S, Grigoriadis T, Chatzipapas I, Protopapas A, Antsaklis A. The vaginally assisted laparoscopic sacrocolpopexy: a pilot study. Int Urogynecol J 2013;24(5):839-845

10 Akladios CY, Dautun D, Saussine C, Baldauf JJ, Mathelin C, Wattiez A. Laparoscopic sacrocolpopexy for female genital organ prolapse: establishment of a learning curve. Eur J Obstet Gynecol Reprod Biol 2010;149(2):218-221

11 Claerhout F, De Ridder D, Roovers JP, et al. Medium-term anatomic and functional results of laparoscopic sacrocolpopexy beyond the learning curve. Eur Urol 2009;55(6):1459-1467

12 Klauschie JL, Suozzi BA, O’Brien MM, McBride AW. A comparison of laparoscopic and abdominal sacral colpopexy: objective out- come and perioperative differences. Int Urogynecol J Pelvic Floor Dysfunct 2009;20(3):273-279

13 Rivoire C, Botchorishvili R, Canis M, et al. Complete laparoscopic treatment of genital prolapse with meshes including vaginal promontofixation and anterior repair: a series of 138 patients. J Minim Invasive Gynecol 2007;14(6):712-718

14 Patel M, O'Sullivan D, Tulikangas PK. A comparison of costs for abdominal, laparoscopic, and robot-assisted sacral colpopexy. Int Urogynecol J Pelvic Floor Dysfunct 2009;20(2):223-228

15 Culligan PJ, Murphy M, Blackwell L, Hammons G, Graham C, Heit $\mathrm{MH}$. Long-term success of abdominal sacral colpopexy using synthetic mesh. Am J Obstet Gynecol 2002;187(6):1473-1480, discussion 1481-1482

16 Imparato E, Aspesi G, Rovetta E, Presti M. Surgical management and prevention of vaginal vault prolapse. Surg Gynecol Obstet 1992;175(3):233-237

17 Brizzolara S, Pillai-Allen A. Risk of mesh erosion with sacral colpopexy and concurrent hysterectomy. Obstet Gynecol 2003; 102(2):306-310

18 Rosati M, Bramante S, Conti F. A review on the role of laparoscopic sacrocervicopexy. Curr Opin Obstet Gynecol 2014;26; (4):281-289 